sterilizing power, and $\mathrm{NH}_{4}$ salts have a somewhat long surviving period for bacteria.

(4) At the same molecular concentration of acids having the same number of $\mathrm{C}$ atom, from $\mathrm{C}_{2}$ to $\mathrm{C}_{3}$ acids, dibasic fatty acid is the strongest, unsaturated monobasic fatty acid is the next, and saturated monobasic fatty acid is the weakest. The fact is chiefly due to $\mathrm{pH}$. From $\mathrm{C}_{5}$ acid, according to the increase of the number of $\mathrm{C}$ atom, the sterilizing action of monobasic fatty acids are stronger than those of dibasic fatty acids. The fact due to the effect of undissociated molecules of each acids.

(5) At the same $\mathrm{pH}$, sterilizing action of saturated monobasic fatty acid is the strongest, unsaturated monobasic fatty acid is the next and didasic fatty acid is the weakest of all. The fact is due to the difference of molecular concentration of each acids.

(6) There is no special relation between the number of $\mathrm{CO}_{2} \mathrm{H}$ group and the strength of sterilizing action.

Refference.

(1) S. Terssumoto: The Bul, of the Agr. chem. S, of Iap. Vol. 9, Nos, 1 3, (1933).

(2)

\title{
Bombilupeol, a Colorless Crystallizable Constituent of the Alcoholic Extract of the Domestic Cocoon, (Résumé)
}

\author{
By \\ Masami OkU
}

(From the Chemical Laboratory of Gunze Raw Silk Mfg, Co. Ltd., Ayahemati, Kyoto-fu, Japan.)

(Received December 11, 1933.)

In the course of my investigation regarding the natural coloring matters of the yellowish green domestic cocoon named "Seihaku", a colorless substance which gave the color reactions of phytosterol was isolated from the ether soluble fraction of the cold alcoholic extract of the cocoon layer in the pure crystallized form and found to be identical with lupeol by its molecular formula and other properties.

The auther decided to give the name of "Bombilupeol" to the substance because no one has yet isolated it not only from domestic cocoon (Bombyx 
mori), but also from animal origin.

\section{Experimental.}

The cold $70 \%$ ethyl alcoholic extract of the cocoon layer was condensed and fractionated into two parts, namely, the ether soluble in which bombilupeol dissolved and the aqueous in which a great part of the yellowish green pigment was dissolved. From the none-saponifiable fraction of the ether soluble part, the pure substance was isolated after repeating the recrystallization from methanol, using animal charcoal. The yield of the pure crystal was about $0.01 \%$ of the cocoon layers.

The substance crystallized out as colorless, needle shaped crystals, sometimes forming radiant colonies with silky appearance. When crystallized out from ether, it formed needles arranged in sheaves. The pure crystal melted sharply at $213^{\circ}$ (corr.) and showed no depression of the melting point by mixing in it the lupeol which was isolated from the bark of "Sikeihi". From the results of analysis the molecular formula was given as $\mathrm{C}_{30} \mathrm{H}_{50} \mathrm{O}$ with one double bond. The rotation in chloroform solution was estimated as $[\alpha]_{\mathrm{D}}^{25}=+$ $27.50^{\circ}$. The substance was insoluble in water, acids or alkalies, sparingly soluble in cold alcohol but soluble in hot alcohol and readily soluble in cold ether, chloroform, benzene and petroleum ether and gave, after long elapse of time, the color reactions of Liebermann-Burchard and others, which being characteristic to phytosterol. On treatment with acetic acid anhydride and benzoyl chloride, the substance was converted respectively into acetate (M. P. $216^{\circ}$ ) and benzoate (M. P. $270^{\mathrm{c}}$ ).

The trial to detect the bombilupeol in the other species of domestic cocoon, eg., yellowish, pale green and white, gave negative results, but a minute quantities of substances gave color reactions of phytosterol was isolated, leaving its further examination in future.

The origin of bombilupeol of the yellowish green cocoon can be presumed as deriving from the mulberry leaves on which silk warm feeds but its detection in the leaves must be carried out by further experiment. 